\title{
How much biomass do plant communities pack per unit volume?
}

Raphael Proulx, Guillaume Rheault, Laurianne Bonin, Irene T Roca, Charles A Martin, Louis Desrochers, Ian S Seiferling

Aboveground production in terrestrial plant communities is commonly expressed in amount of carbon, or biomass, per unit surface. Alternatively, expressing production per unit volume allows the comparison of communities by their fundamental capacities in packing carbon. In this work we reanalyzed published data from more than 900 plant communities across nine ecosystems to show that standing dry biomass per unit volume (biomass packing) consistently averages around $1 \mathrm{~kg} / \mathrm{m}^{3}$ and rarely exceeds $5 \mathrm{~kg} / \mathrm{m}^{3}$ across ecosystem types. Furthermore, we examined how empirical relationships between aboveground production and plant species richness are modified when standing biomass is expressed per unit volume rather than surface. We propose that biomass packing emphasizes species coexistence mechanisms and may be an indicator of resource use efficiency in plant communities. 
2 How much biomass do plant communities pack per unit volume?

3

4 Raphaël Proulx ${ }^{1 *}$, Guillaume Rheault ${ }^{1}$, Laurianne Bonin ${ }^{1}$, Irene Torrecilla Roca ${ }^{1}$, Charles A. Martin ${ }^{1}$, $5 \quad$ Louis Desrochers ${ }^{1}$, Ian Seiferling ${ }^{1}$

6

7

$8{ }^{1}$ Canada Research Chair in Ecological Integrity, Département des Sciences de l'Environnement,

9 Université du Québec à Trois-Rivières, C.P. 500, Trois-Rivières, Québec, G9A 5H7 (Canada)

10

11

$12 *$ Corresponding author : raphael.proulx@uqtr.ca

13

14

15 Short title: Biomass packing in plant communities 


\section{Abstract}

17 Aboveground production in terrestrial plant communities is commonly expressed in amount of carbon,

18 or biomass, per unit surface. Alternatively, expressing production per unit volume allows the

19 comparison of communities by their fundamental capacities in packing carbon. In this work we

20 reanalyzed published data from more than 900 plant communities across nine ecosystems to show that

21 standing dry biomass per unit volume (biomass packing) consistently averages around $1 \mathrm{~kg} / \mathrm{m}^{3}$ and

22 rarely exceeds $5 \mathrm{~kg} / \mathrm{m}^{3}$ across ecosystem types. Furthermore, we examined how empirical relationships

23 between aboveground production and plant species richness are modified when standing biomass is

24 expressed per unit volume rather than surface. We propose that biomass packing emphasizes species

25 coexistence mechanisms and may be an indicator of resource use efficiency in plant communities.

\section{Introduction}

28 Uncovering general principles that govern the functioning of ecosystems is a long standing objective of

29 community ecology. One such principle, the self-thinning rule, predicts that the standing biomass of

30 plant communities increases with decreasing stem density in crowded stands (Hutchings, 1979,

31 Westoby, 1984). D.E. Weller (1989) proposed a simple geometric model of the self-thinning rule in

32 which the standing biomass $\left(\mathrm{g} / \mathrm{m}^{2}\right)$ of different communities is negatively correlated to stem density.

33 When expressed per unit volume $\left(\mathrm{g} / \mathrm{m}^{3}\right)$ however, his model also predicted that standing biomass

34 should be independent of stem density across the plant kingdom (Weller, 1989).

35 Absence of a general relationship between standing biomass per unit volume and stem density across a

36 range of ecosystems would have two important implications. First, it would evince that plants cannot

37 allocate more carbon to aboveground compartments than imposed by competition for volumetric 
38 resources, such as light. Secondly, plant communities would differ from one another in their capacity

39 to grow tall, yet compare in their capacity to pack carbon. Weller (1989) reported a positive

40 relationship between dry biomass per unit volume and stem density, suggesting more efficient carbon

41 packing in communities growing at a higher density. However, Weller's relationship relied on two

42 datasets and, thus, remains inadequately tested.

43 Aboveground production, or yield, in terrestrial plant communities is commonly measured in amount

44 of dry biomass per unit surface. Alternatively, expressing production per unit volume could better

45 reflect how plants utilize all dimensions of the space in which they grow, hence emphasizing

46 coexistence mechanisms. For instance, plants adapted to grow in the shade may contribute to biomass

47 packing by filling the understorey space more efficiently (Claveau, Messier \& Comeau, 2005,

48 Valladares \& Niinemets, 2008). Moreover, plants characterized by different growth rates or lifespans

49 may increase biomass packing by acquiring resources on different spatial or time scales (Augspurger,

50 2008).

51 Biomass packing can be conceptualized as the amount of standing vegetation living within a sampling

52 box. This box delineates a three-dimensional space, either physical or virtual, within which the

53 vegetation is confined. Thus, biomass packing represents the amount of standing vegetation (expressed

54 as dry biomass or occupied plant volume) scaled per unit of sampled volume.

55 The present study addresses two questions: Are there fundamental limits to the amount of standing dry

56 biomass that is packed per unit volume in terrestrial plant communities? Is biomass packing affected by

57 community composition and species richness? To investigate these questions we reviewed the

58 scientific literature and compiled data for more than 900 plant communities. This synthesis highlights

59 broad patterns in biomass packing across contrasted ecosystem types. It is not a meta-analysis of the 
60 reviewed literature, which would require the inclusion of climatic or edaphic moderator variables as

61 well as accounting for spatial auto-correlation and random (data source) effects.

\section{Materials \& Methods}

64 We searched the scientific literature for studies reporting both dry standing biomass per unit surface

65 and mean height of canopy plants in vegetation stands. The search targeted studies that monitored

66 vegetation stands close to their peak of biomass production (Table 1). We converted all biomass values

67 to $\mathrm{g} / \mathrm{m}^{2}$ and height values to $\mathrm{m}$ (Table $\mathrm{S} 1$ ). In the literature, we found only Weller's study (1989)

68 reported direct measures of biomass per unit volume in terrestrial ecosystems. As such, Weller's

69 dataset was not used in our analysis, but as a benchmark to compare those results against. From all

70 other aggregated data, we calculated the packing density of each plant community by dividing standing

71 dry biomass per unit surface by community height.

72 In addition to biomass and height, three of the data sources also included the species richness of their

73 respective plant community (Table S1): meadow, wetland and grassland. This data subset of 533

74 communities allowed us to examine how expressing standing biomass per unit surface or unit volume

75 modifies the relationship between biomass production and plant species richness.

76 To determine whether standing dry biomass approximates the volume occupied by plants, we compiled

77 a dataset on 42 wetland plant communities from the Lac St-Pierre ecosystem (Québec, Canada). In

78 August 2014, we sampled vegetation quadrats of $0.5 \times 0.5 \mathrm{~m}$ covering a broad range of species

79 assemblages and vegetation types. In each quadrat we clipped all the vegetation standing above $2 \mathrm{~cm}$

80 from the ground. We then evaluated plant volume using the water displacement method in a bucket of

$8112.6 \mathrm{~cm}$ radius. We expressed the amount of water displaced by the submersed vegetation in cubic 
meters. We then oven dried the vegetation at $70^{\circ} \mathrm{C}$ for $48 \mathrm{~h}$ and weighed the dry biomass. Finally, we report the relationship between plant volume $\left(\mathrm{m}^{3} / \mathrm{m}^{2}\right)$ and standing dry biomass $\left(\mathrm{g} / \mathrm{m}^{2}\right)$ to evaluate their association.

\section{Results}

From our analysis of the reviewed data we found that standing dry biomass per unit surface varied by over three orders of magnitude across the plant kingdom (Fig. 1). In forest ecosystems, dry biomass per unit surface typically ranged between 10 and $100 \mathrm{~kg} / \mathrm{m}^{2}$, with pacific and tropical forest communities consistently reaching higher values than that of temperate and boreal forests. In contrast, the standing biomass of croplands and grasslands was comparable to one another, falling just above $1 \mathrm{~kg} / \mathrm{m}^{2}$ on average. Lastly, meadows cumulated around $0.3 \mathrm{~kg} / \mathrm{m}^{2}$ standing dry biomass, though biomass increased with increasing species richness, up to $0.5 \mathrm{~kg} / \mathrm{m}^{2}$ in the 60 -species communities (slope $=0.0037, \mathrm{R}^{2}=$ $0.06, \mathrm{df}=338, \mathrm{t}=4.5, \mathrm{p}<0.001)$

When expressing the standing dry biomass of the 971 communities in our dataset per unit volume, biomass packing varied around $1 \mathrm{~kg} / \mathrm{m}^{3}$ (the average $50^{\text {th }}$ percentile being $0.88 \mathrm{~kg} / \mathrm{m}^{3}$ ) and by less than an order of magnitude across ecosystems (Fig. 1). The $75^{\text {th }}$ percentile for biomass packing across ecosystems ranged from $0.81 \mathrm{~kg} / \mathrm{m}^{3}$ in croplands up to $1.82 \mathrm{~kg} / \mathrm{m}^{3}$ in pacific forests, suggesting high overall consistency relative to measures of biomass per unit surface (Fig. 1). Biomass packing reached an overall maximum at $4.7 \mathrm{~kg} / \mathrm{m}^{3}$ in one pacific forest plot.

The positive relationship between plant species richness and biomass production among experimental meadow communities vanished when standing dry biomass was expressed per unit volume rather than surface (slope $=0.0004, \mathrm{R}^{2}<0.01, \mathrm{df}=338, \mathrm{t}=0.3, \mathrm{p}=0.738$, Fig. 1). In other herbaceous ecosystems 
104 (Fig. 2), the relationship between plant species richness and biomass production shifted from negative,

105 when biomass was expressed per unit surface ( slope $=-0.063, \mathrm{R}^{2}=0.12, \mathrm{df}=191, \mathrm{t}=-5.2, \mathrm{p}<0.001$ ),

106 to nonexistent when expressed per unit volume (slope $=0.018, \mathrm{R}^{2}<0.01, \mathrm{df}=191, \mathrm{t}=1.3, \mathrm{p}=0.180$ ).

107 We compared two methods of quantifying the amount of standing vegetation for wetland plant

108 communities. The relationship between dry biomass and plant volume was strong and linear (Pearson's

$109 \mathrm{r}=0.86$ ), indicating that standing biomass is a good proxy for the volume occupied by plant modules,

110 at least for wetland communities (Fig. 3).

\section{Discussion}

\section{Fundamental limits to biomass packing}

114 The literature review highlights that if plant community biomass is represented as dry biomass per unit

115 surface area, major ecosystem types are drastically different. However, when accounting for height and

116 expressing standing dry biomass per unit volume, plant communities from different ecosystems appear

117 remarkably similar in their capacity to pack biomass. Biomass packing across plant communities

118 peaked just below $5 \mathrm{~kg} / \mathrm{m}^{3}$, with an average median across ecosystems close to $1 \mathrm{~kg} / \mathrm{m}^{3}$. These values

119 are strikingly similar to those originally reported by Weller (1989) for mono-specific stands; reporting

120 a maximum value of $5.2 \mathrm{~kg} / \mathrm{m}^{3}\left(\right.$ median of $1.2 \mathrm{~kg} / \mathrm{m}^{3}$ ) in the first dataset and $5.3 \mathrm{~kg} / \mathrm{m}^{3}$ (median of 0.6

$121 \mathrm{~kg} / \mathrm{m}^{3}$ ) in the second. We feel confident that the inclusion of more plant communities would not alter

122 these general results.

123 Our results revealed that cropland and meadow communities were equally capable of packing biomass

124 per unit volume. However, the caveat to this result is that it is true only when plant communities are 
125 compared at their peak of biomass production. For instance, cornfields sown in widely spaced rows

126 attain their maximum of biomass packing only towards the end of the growing season. Likewise,

127 meadows are repeatedly harvested within a year, after which a regrowth period of sparse vegetation

128 and low biomass packing initiates. Moreover, while tropical and temperate forests may show similar

129 packing values at their peak of production, air temperature and sunlight duration impose stronger

130 seasonal variations in the biomass packing of temperate ecosystems. Such examples illustrate the

131 importance of accounting for changes in biomass packing over time and, perhaps, the inaccuracy of

132 treating it as a static metric.

133 Perhaps the most contentious issue when assessing biomass packing is how the vertical dimension of

134 the sampling box is measured. Here, the upper boundary of that box was defined as the mean height of

135 canopy plants. In our review, one case study did use a physical, rather than a virtual, sampling box to

136 assess the biomass packing of young (<18 years old) forest stands (Peterson et al., 1982). In this study,

137 sampling boxes of $1 \mathrm{~m}^{3}$ were placed in 107 woody stands, such that stems would fill the frames from

138 top to bottom. Overall, the maximum biomass packing measured across stands and vegetation types

139 varied from $3 \mathrm{~kg} / \mathrm{m}^{3}$ in poplar and birch forests to $6 \mathrm{~kg} / \mathrm{m}^{3}$ in pine and spruce forests (Peterson et al.,

140 1982). Since sampling frames in this study were systematically placed in the densest portions of the

141 forest, the above values represent upper bounds of dry biomass per unit volume. Hence, although

142 measures of community height among studies might differ slightly, the biomass packing limit of ca. 5

$143 \mathrm{Kg} / \mathrm{m}^{3}$ that we identified is in fair agreement with the upper bounds independently reported by Peterson

144 et al. (1982) and Weller (1989).

145 Species richness and biomass packing 
146 Garnering much attention in the literature, positive relationships between species richness and biomass

147 production have been repeatedly reported in experimentally manipulated plant communities (e.g.,

148 Reich et al. 2012). Further analyses of such experiments have determined that the relationship arises

149 from a more efficient use of resources in species-rich communities over that of species-poor ones, or

150 the so-called complementarity effect (Cardinale et al. 2007, Reich et al. 2012). Plant communities in

151 the Jena Biodiversity Experiment, also used here as a data source, are no exception to this trend

152 (Marquard et al. 2009). In contrast to the positive relationship between species richness and biomass

153 per unit surface, our results show that species-rich meadows in the Jena Experiment do not pack more

154 biomass per unit volume; that is, the richness-packing relationship is flat.

155 Divergent from those aforementioned biodiversity experiments, a negative relationship between plant

156 species richness and biomass production can be observed in freely assembled herbaceous communities,

157 wherein the productive stands are dominated by fewer species (Waide et al. 1999). The negative tail of

158 the richness-production relationship has been explicated by facilitation and competitive exclusion

159 processes among plant species growing in the most fertile situations (e.g., Michalet et al. 2006). In the

160 present study, we did observe a higher biomass per unit surface in species-poor herbaceous

161 communities, and therefore a negative richness-production relationship, but again the relationship

162 vanished when standing dry biomass was expressed per unit volume. Stated simply, plant species

163 richness had no effect on the biomass packing of plant communities at their peak of production.

164 To understand why the richness-biomass relationship flattens when expressing biomass per unit

165 volume, we examined how much of the variation in standing biomass per unit surface is explained by

166 community height. Among our 971 plant communities, height explains $88 \%$ of the variation in

167 standing biomass when the axes are on a logarithmic scale (Table S1). This strong correlation suggests

168 that, both, community height and biomass per unit surface are likely driven by similar factors affecting 
169 resource use and availability (Moles et al. 2009). Dividing standing dry biomass by community height

170 would emphasize the local species coexistence processes that are independent of stand fertility and

171 climate conditions, but the assertion remains to be fully tested.

173 Conclusions

174 Our reanalysis of the literature casts a new light on how plant biomass accumulates in terrestrial

175 ecosystems. Specifically, while the widespread metric of biomass per unit surface highlights

176 differences between plant communities, expressing their standing dry biomass per unit of volume

177 reveals their striking similarity. Expressing biomasses per unit volume goes against a longstanding

178 tradition of measuring primary production per unit surface in terrestrial ecosystems, probably reflecting

179 our utilitarian view of ecosystems conditioned by questions such as: how much crop (e.g., wood, hay,

180 or grain) can be produced and harvested per hectare of land?

181 Our findings suggest that biomass packing is influenced less by baseline climatic and edaphic

182 conditions, but rather emphasizes local plant-plant interactions. We propose that a fundamental limit

183 might exist to the amount of dry biomass that natural plant communities pack per unit volume in

184 terrestrial ecosystems; since the long-term maintenance of standing dry biomass beyond this point may

185 be biologically unsustainable (Hutchings 1979). It is likely that this approximate limit of $5 \mathrm{~kg} / \mathrm{m}^{3}$ can

186 be exceeded in communities grown under controlled conditions, although croplands did not reach

187 higher biomass packing values over that of other ecosystems in our dataset. Biomass packing may thus

188 represent a simple and generic indicator of resource use efficiency in plant communities. 
190

191

192

193

194

195

196

197

198

199

200

201

202

203

204

205

206

207

208 209

\section{References}

Augspurger, C.K. 2008. Early spring leaf out enhances growth and survival of saplings in a temperate deciduous forest. Oecologia 156:281-286.

Cardinale, B. J., J. P. Wright, M. W. Cadotte, I. T. Carroll, A. Hector, D. S. Srivastava, M. Loreau, and J. J. Weis. 2007. Impacts of plant diversity on biomass production increase through time because of species complementarity. Proceedings of the National Academy of Sciences of the United States of America 104:18123-18128.

Claveau Y., C. Messier, and P. G. Comeau. 2005. Interacting influence of light and size on aboveground biomass distribution in sub-boreal conifer saplings with contrasting shade tolerance. Tree physiology 25:373-384.

Gillis, M.D., A. Y. Omule, and T. Brierley. 2005. Monitoring Canada's forests: The national forest inventory. Forestry Chronicle 81:214-221.

Hutchings, M.J. 1979. Weight-density relationships in ramet populations of clonal perennial herbs, with special reference to the-3/2 power law. Journal of Ecology 67:21-33.

Marquard, E., A. Weigelt, V. M. Temperton, C. Roscher, J. Schumacher, N. Buchmann, M. Fischer, W. W. Weisser, and B. Schmid. 2009. Plant species richness and functional composition drive overyielding in a six-year grassland experiment. Ecology 90:3290-3302.

Michalet, R., R. W. Brooker, L. A. Cavieres, Z. Kikvidze, C. J. Lortie, F. I. Pugnaire, A. Valiente-Banuet, and R. M. Callaway. 2006. Do biotic interactions shape both sides of the humped-back model of species richness in plant communities? Ecology Letters 9:767-773. 
210 Moles, A.T., D. I. Warton, L. Warman, N. G. Swenson, S. W. Laffan, A. E. Zanne, A. Pitman, F. A.

211 Hemmings, and M. R. Leishman. 2009. Global patterns in plant height. Journal of Ecology 97:923212932.

213 Peterson, E. B., R. D. Kabzems, and V.W. Levson. 1982. Upper limits of standing crop density for 214 woody species in the prairie provinces. Vol. 243. Northern Forest Research Centre, Canadian 215 Forestry Service, Environment Canada.

216 Propheter, J.L., S. A.Staggenborg, X. Wu, and D. Wang. 2010. Performance of annual and perennial 217 biofuel crops: yield during the first two years. Agronomy Journal 102:806-814.

218 Reich, P.B., D. Tilman, F. Isbell, K. Mueller, S. E. Hobbie, D. F. Flynn, and N. Eisenhauer. 2012.

219 Impacts of biodiversity loss escalate through time as redundancy fades. Science 336:589-592.

220 Rheault, G., R. Proulx, and L. Bonin. 2015. Plant species richness prolongs the growing season of 221 freely assembled riparian herbaceous communities under dry climatic conditions. Agriculture 222 Ecosystems \& Environment 200:71-78.

223 Valladares, F., and Ü. Niinemets. 2008. Shade tolerance, a key plant feature of complex nature and 224 consequences. Annual Review of Ecology, Evolution, and Systematics 39:237-257.

225 Violle, C., A. Bonis, M. Plantegenest, C. Cudennec, C. Damgaard, B. Marion, D. Le Cœur, and J. B. 226 Bouzillé. 2011. Plant functional traits capture species richness variations along a flooding gradient. 227 Oikos 120:389-398.

228 Yamakura, T., A. Hagihara, S. Sukardjo, and H. Ogawa. 1986. Aboveground biomass of tropical rain 229 forest stands in Indonesian Borneo. Vegetatio 68:71-82. 
230 Waide, R.B., M. R. Willig, C. F. Steiner, G. Mittelbach, L. Gough, S. I. Dodson, J. P. Juday, and R. 231 Parmenter. 1999. The relationship between productivity and species richness. Annual Review of 232 Ecology and Systematics 30:257-300.

233 Weaver, P.L., and P. G. Murphy. 1990. Forest structure and productivity in Puerto Rico's Luquillo 234 Mountains. Biotropica 22:69-82.

235 Weigelt, A., E. Marquard, V. M. Temperton, C. Roscher, C. Scherber, P. N. Mwangi, S. von Felten, N. 236 Buchmann, B. Schmid, and E-D. Schulze. 2010. The Jena Experiment: six years of data from a 237 grassland biodiversity experiment: Ecological Archives E091-066. Ecology 91:930-931.

238 Weller, D.E. 1989. The interspecific size-density relationship among crowded plant stands and its 239 implications for the-3/2 power rule of self-thinning. American naturalist 133:20-41.

240 Westoby, M. 1984. The self-thinning rule. Advances in Ecological Research 14:167-225.

241 Wilhelm, W.W., J. M. Johnson, D. T. Lightle, D. L. Karlen, J. M. Novak, N. W. Barbour, D. A. Laird, 242 J. Baker, T. E. Ochsner, and A. D. Halvorson. 2011. Vertical distribution of corn stover dry mass 243 grown at several US locations. BioEnergy Research 4:11-21.

244 Whittaker, R.H., F. H. Bormann, G. E. Likens, and T. G. Siccama. 1974. The Hubbard Brook 245 ecosystem study: forest biomass and production. Ecological Monographs 44:233-254. 


\section{Figure captions}

248 Fig. 1. Standing dry biomass of plant communities in different ecosystems when biomass is expressed

249 (a) per unit surface or (b) per unit volume.

250 Fig. 2. Relationship between species richness and dry standing biomass of plant communities in two

251 herbaceous ecosystems when biomass is expressed (a) per unit surface or (b) per unit volume.

252 Fig. 3. Comparison of two methods of assessing the amount of standing vegetation in wetlands of the 253 Lac St-Pierre (Québec, Canada). The aboveground production of 42 plant communities is expressed in 254 units of dry biomass $\left(\mathrm{g} / \mathrm{m}^{2}\right)$ or of occupied plant volume $\left(\mathrm{m}^{3} / \mathrm{m}^{2}\right)$ 
Figure 1 (on next page)

Standing dry biomass of plant communities in different ecosystems when biomass is expressed (a) per unit surface or (b) per unit volume. 
Figure 2 (on next page)

Relationship between species richness and dry standing biomass of plant communities in two herbaceous ecosystems when biomass is expressed (a) per unit surface or (b) per unit volume. 
PeerJ Reviewing Manuscript
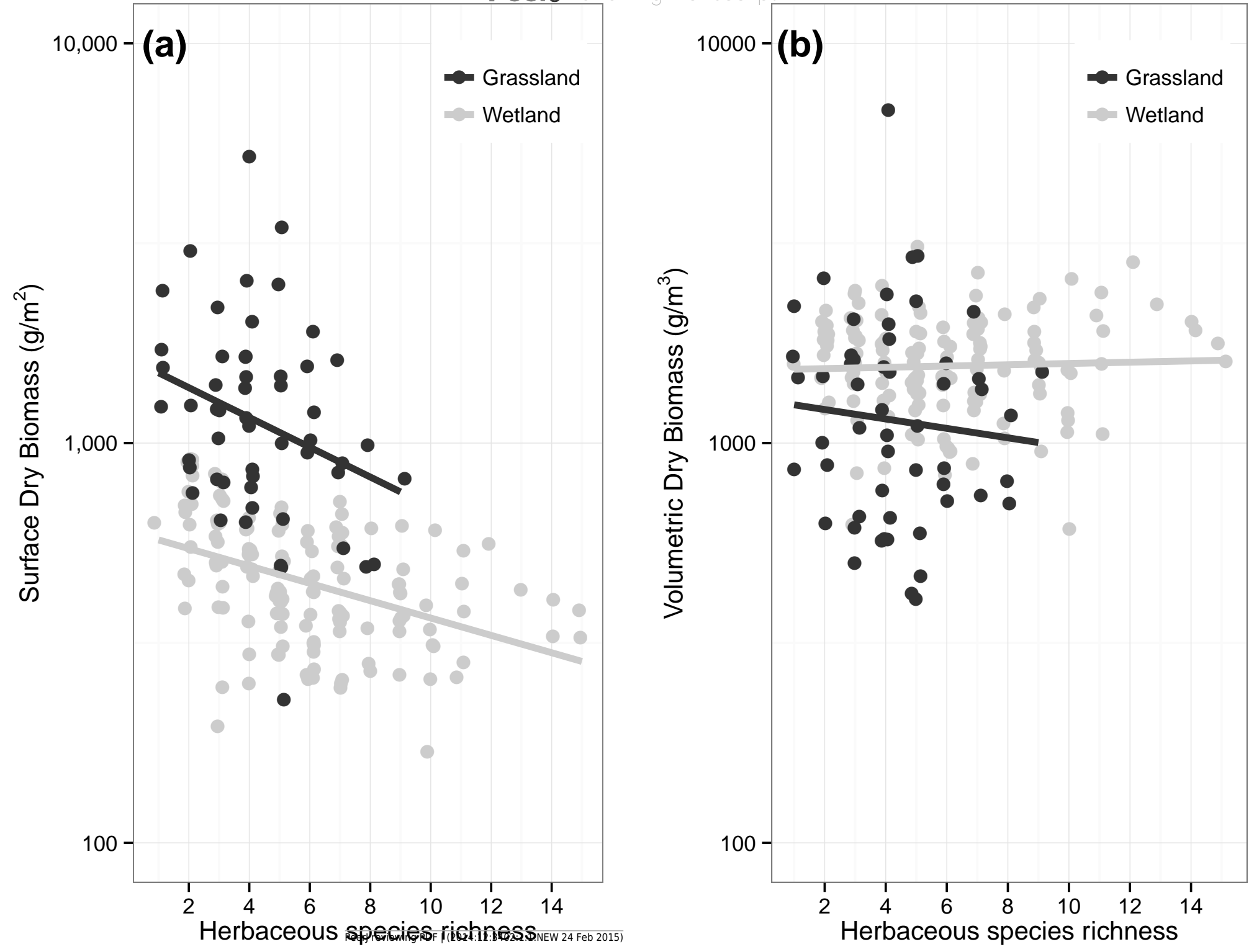
Figure 3 (on next page)

Comparison of two methods of assessing the amount of standing vegetation in wetlands of the Lac St-Pierre (Québec, Canada).

The aboveground production of 42 plant communities is expressed in units of dry biomass $\left(\mathrm{g} / \mathrm{m}^{2}\right)$ or of occupied plant volume $\left(\mathrm{m}^{3} / \mathrm{m}^{2}\right)$. 
PeerJ Reviewing Manuscript

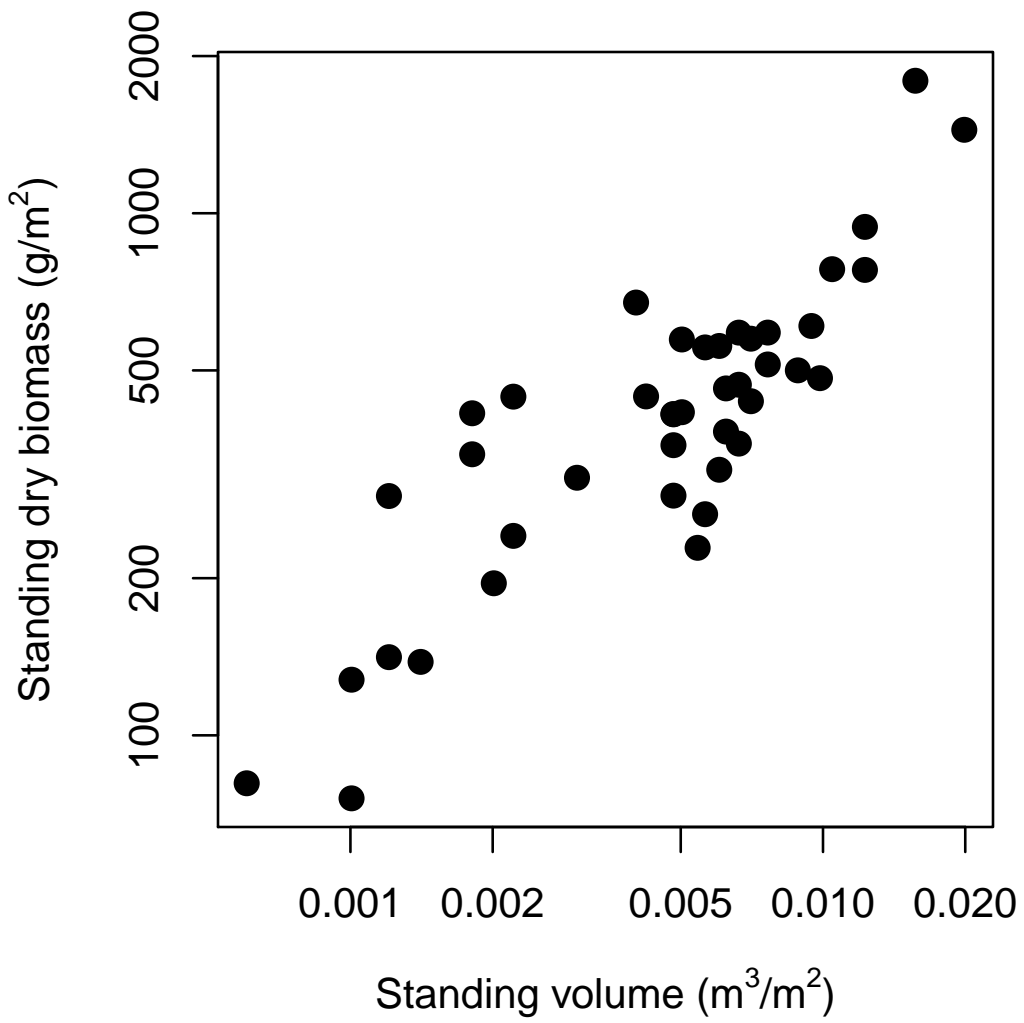




\section{Table $\mathbf{1}$ (on next page)}

Ecosystems and plant communities (No. stands) from various sources reporting both total dry standing biomass per unit surface and mean height of canopy plants. 


\begin{tabular}{|c|c|c|c|}
\hline Ecosystem & $\begin{array}{l}\text { No. } \\
\text { stands }\end{array}$ & Location & Sources \\
\hline Croplands - Biofuel & 19 & USA & $\begin{array}{l}\text { (Propheter et al. } \\
\text { 2010) }\end{array}$ \\
\hline Cropland - Corn & 13 & USA & $\begin{array}{l}\text { (Wilhelm et al. } \\
\text { 2011) }\end{array}$ \\
\hline Forest - Tropical & 19 & $\begin{array}{l}\text { Columbia, } \\
\text { Cambodia, } \\
\text { Thailand, } \\
\text { Venezuela, } \\
\text { Malaysia, Borneo, } \\
\text { Puerto Rico }\end{array}$ & $\begin{array}{l}\text { (Yamakura et al. } \\
\text { 1986, Weaver and } \\
\text { Murphy 1990) }\end{array}$ \\
\hline Forest - Pacific (west-coast) & 45 & Canada & (Gillis et al. 2005) \\
\hline Forest - Temperate & 174 & USA, Canada & $\begin{array}{l}\text { (Whittaker et al. } \\
\text { 1974, Gillis et al. } \\
\text { 2005) }\end{array}$ \\
\hline Forest - Boreal & 126 & Canada & (Gillis et al. 2005) \\
\hline Grasslands & 53 & Canada & (Rheault et al. 2014) \\
\hline Meadows $-8,16 \& 60$ species & 340 & Germany & $\begin{array}{l}\text { (Weigelt et al. } \\
\text { 2010) }\end{array}$ \\
\hline Wetlands & 182 & $\begin{array}{l}\text { France, } \\
\text { Canada }\end{array}$ & $\begin{array}{l}\text { (Violle et al. 2011, } \\
\text { Proulx et al., } \\
\text { unpublished } \dagger \text { ) }\end{array}$ \\
\hline
\end{tabular}

$2 \uparrow$ Data are presented in Appendix 1 